\title{
Support of the collaborative inquiry learning process: influence of support on task and team regulation
}

\author{
Nadira Saab • Wouter van Joolingen • \\ Bernadette van Hout-Wolters
}

Received: 31 January 2009 / Accepted: 24 January 2011 /

Published online: 1 March 2011

(C) The Author(s) 2011. This article is published with open access at Springerlink.com

\begin{abstract}
Regulation of the learning process is an important condition for efficient and effective learning. In collaborative learning, students have to regulate their collaborative activities (team regulation) next to the regulation of their own learning process focused on the task at hand (task regulation). In this study, we investigate how support of collaborative inquiry learning can influence the use of regulative activities of students. Furthermore, we explore the possible relations between task regulation, team regulation and learning results. This study involves tenth-grade students who worked in pairs in a collaborative inquiry learning environment that was based on a computer simulation, Collisions, developed in the program SimQuest. Students of the same team worked on two different computers and communicated through chat. Chat logs of students from three different conditions are compared. Students in the first condition did not receive any support at all (Control condition). In the second condition, students received an instruction in effective communication, the RIDE rules (RIDE condition). In the third condition, students were, in addition to receiving the RIDE rules instruction, supported by the Collaborative Hypothesis Tool (CHT), which helped the students with formulating hypotheses together (CHT condition). The results show that students overall used more team regulation than task regulation. In the RIDE condition and the CHT condition, students regulated their team activities most often. Moreover, in the CHT condition the regulation of team activities was positively related to the learning results. We can conclude that different measures of support can enhance the use of team regulative activities, which in turn can lead to better learning results.
\end{abstract}

Keywords Collaborative inquiry learning $\cdot \operatorname{cscl} \cdot$ Metacogntion $\cdot$ Task regulation $\cdot$ Team regulation · Support - Instruction

\footnotetext{
N. Saab $(\bowtie)$

Leiden University, Wassenaarseweg 52, 2333 AK Leiden, The Netherlands

e-mail: nsaab@fsw.leidenuniv.nl

W. van Joolingen

University of Twente, Enschede, Netherlands

B. van Hout-Wolters

University of Amsterdam, Amsterdam, Netherlands
} 


\section{Introduction}

In collaborative inquiry learning, students work together in a learning environment doing experiments and using the results for shared knowledge construction (De Jong 2006; Kuhn et al. 2000; Saab et al. 2005). Computer simulations can be used to execute these experiments in a safe and easily accessible environment (Njoo and De Jong 1993; Njoo 1994; De Jong and Van Joolingen 1998). Examples of such collaborative inquiry learning environments are Co-Lab (Van Joolingen et al. 2005) or WISE (Linn et al. 2004). Inquiry learning and collaborative learning have separately been studied systematically (e.g., De Jong and Van Joolingen 1998; Van der Linden et al. 2000).

In an inquiry learning environment, students can use a scientific approach to learning in order to discover rules of the domain or solve problems. Inquiry learning processes include orientation, generating hypotheses, testing these hypotheses and drawing conclusions (Kuhn et al. 2000). De Jong and Njoo (1992) label these processes as transformative processes, which can lead to the generation of knowledge and new information. Next to these transformative processes, De Jong and Njoo (1992) distinguish regulative inquiry processes, such as monitoring and evaluating, which can help the student to regulate the use of the transformative processes.

Although inquiry learning can be a useful didactic method, by itself it may not result in learning gain. Additional support and guidance for inexperienced learners is needed (Klahr and Nigam 2004; Mayer 2004). Collaborative learning can positively affect the quality of the learning process and can lead to the construction of new knowledge (e.g., Cohen 1994; Springer et al. 1999; Van Boxtel 2000; Van der Linden et al. 2000). Merging collaborative learning with inquiry learning can support students inquiry learning process and improve their learning performance (e.g., Okada and Simon 1997; Whitelock et al. 1995). When students are collaborating, they can exchange ideas by asking questions, giving explanations, and negotiating (Chi et al. 1989; Dekker and Elshout-Mohr 1998; King 1997). In a collaborative inquiry learning environment, students can make decisions together on which activities to execute and how to solve the problem. However, the exchange of facts and ideas is not enough to lead to effective learning (Baker and Lund 1997; Webb et al. 2002). Task-focused and elaborated interaction that includes all collaborating students is required to facilitate learning (Kaartinen and Kumpulainen 2002). Students need to understand and agree with the contributions of their peers in order to construct knowledge together (De Vries et al. 2002; Van Boxtel 2000).

\section{Support of collaborative inquiry learning}

Next to introducing the combination of collaboration with inquiry learning, several forms of guidance have been developed in order to support the inquiry learning process (De Jong 2006; Linn et al. 2006; Reiser 2004; Sharma and Hannafin 2007). Cognitive tools (Lajoie 1993; Van Joolingen 1999), which do not deliver direct instruction but instead offer scaffolds to help students with the execution of cognitive tasks, can be used in different processes of inquiry learning. Examples are tools to support hypotheses generation (Van Joolingen and De Jong 1993; Saab 2005; Shute and Glaser 1990), or tools to support monitoring (Veermans et al. 2000).

Cognitive tools can serve as scaffolds for processes of inquiry learning that students find difficult. However, students who are working in a collaborative inquiry learning environment not only find it difficult to go through the inquiry processes efficiently; they often do not know how to collaborate effectively. Collaboration without instruction or 
means of support does not necessarily lead to an effective collaborative learning process or learning outcome (Chan 2001; Mercer 1996; Ross and Cousins 1995; Webb and Farivar 1994). An example of instruction in effective communication is the set of communication guidelines of King (1997), which support the process of peer tutoring by instructing students how to communicate effectively. An example of tools that support students' collaboration process are sentence openers that structure students' communication (e.g., Baker and Lund 1997; Soller 2004). In addition, tools aimed at improving the inquiry learning process can affect the collaboration process as well. For example, tools can be used to present a shared conception of the problem. When using these tools, students can externalize their ideas based on this shared conception. In this way, students are supported with the inquiry learning process and stimulated to discuss the problem at the same time. The Explanation Builder (Sandoval and Reiser 2004) and the Collaborative Hypothesis Tool (Saab 2005) are examples of tools that support both the inquiry learning process as well as the collaborative process. Students can use these tools to formulate hypotheses.

\section{Regulation in collaborative inquiry learning}

In inquiry learning, Njoo and De Jong (1993) distinguish transformative from regulative inquiry learning processes. The latter resembles the regulative phases belonging to the problem solving process: orientation, planning, execution, and evaluation (De Jong et al. 2005; Winne 2005). To go through these phases in an efficient way an effective working method, which can be defined as the application of metacognitive skills, is needed (Veenman et al. 1997). This working method consists of regulative activities (e.g., Boekaerts and Simons 1993; Schraw and Moshman 1995), which regulate the cognitive processes in selecting goals and strategies (planning), implementing those strategies, and monitor and evaluate the learning process (Schunk 1996).

The regulation of cognitive processes can facilitate learning and can lead to better achievement (Hogan et al. 1999; Zimmerman and Schunk 1989) in different domains (Schunk and Zimmerman 1994), such as science (White and Frederiksen 1998). According to several researchers metacognitive skills are needed in the process of inquiry learning (Hogan 1999; Kuhn and Pearsall 1998; Toth et al. 2002; White and Frederiksen 1998). Inquiry learning environments are often computer supported environments, since computer simulations can be used to present learning domains that are not possible to investigate in reality (De Jong 1991). Learning in computer based learning environments (CBLEs) requires regulation of this learning process (Azevedo 2007). CBLEs often consist of illstructured learning tasks. In such environments, students need to make various choices and need to monitor and self-evaluate their learning process. Self-regulation of their learning process is essential (Paris and Paris 2001; Patrick and Middleton 2002).

In the case of computer-supported collaborative learning environments (CSCL environments), such as collaborative inquiry learning environments, regulation of the collaborative learning process is very important (Erkens et al. 2005). An additional aspect is that students not only have to regulate the collaborative problem solving process (task regulation), but also the processes involved with collaboration (itself). In media synchronicity, two different team tasks are distinguished: conveyance and convergence (Weick and Meader 1993). Conveyance refers to the exchange of information and subsequent deliberation on its meaning, whereas convergence represents the development of shared meaning for information. Maruping and Agarwal (2004) argue that convergence processes are best supported by communication environments enabling high immediacy of feedback and low 
parallelism, such as chat. In contrast, communication environments enabling low immediacy of feedback and high parallelism, such as discussion forums, are posited to support the conveyance process.

Just as inquiry learning environments often contain ill-structured learning tasks, collaborative inquiry learning environments do also often have little structure and exists of learning tasks that are open ended (De Jong et al. 2005; Salovaara 2005). Analyzing the team task in terms of media synchronicity, a collaborative inquiry task often is a convergence task, as in the end, learners need to share a mental model of the domain investigated. We study such collaborative inquiry in the context of a shared work space in which learners communicate through chat. In such environments, regulation of task performance is essential. In the process of converging their thoughts, collaborating students have to regulate their interaction, too (Jermann and Dillenbourg 2008; Erkens et al. 2005). For instance, they need not only to check whether they understood a solution themselves, in addition they need to check whether team members share their understanding. In collaborative inquiry learning, students have to plan and organize the process of accomplishing the tasks, in addition to deciding and agreeing on the distribution of cognitive activities that need to be done in order to reach their common goal. Students regulate their interaction by discussing their plans and strategies, supporting each other by giving positive evaluations (Patrick and Middleton 2002), asking each other monitoring questions (Hmelo-Silver and Barrows 2008), and reflecting on each others' ideas.

In this study, we distinguish task regulation, which is aimed at regulating the cognitive activities during learning, and team regulation, which implies the coordination of the collaboration between students, such as checking each others' opinions. In collaborative inquiry learning, task regulation cannot completely be seen as an individual process, since students who work in a CSCL environment have to solve problems together. This means that students who comment on the task from their own individual perspective, which is a self-regulated activity, still share information and, as a result, contribute to the collaborative learning process.

Earlier it was mentioned that tools in computer-supported learning environments can be used to support inquiry learning as well as collaboration. In addition, learning environments can also provide scaffolds that support the regulation of the learning process (Soller et al. 2005). This support is needed since students find it not always easy to regulate their learning in computer-supported learning environments (Azevedo et al. 2004; Hannafin and Land 1997).

In this study, we present two measures to support the collaborative inquiry process: an instruction in effective communication (the RIDE rules, Saab et al. 2007) and a cognitive tool to support the formulation of hypotheses and assist students with the inquiry learning process by prompting them to carry out inquiry activities (the Collaborative Hypothesis Tool, Saab et al. 2005). The aim of this article is to examine the relation between two kinds of support and the regulation of the collaborative inquiry learning process and learning performance. This article focuses on the following questions:

1) What is the influence of support of collaborative inquiry learning on task and team regulation of students?

2) Do different kinds of support affect the regulation of the learning process differently?

3) What is the relation between task and team regulation and the learning results?

We expect that support for effective communication will lead to more regulation of the learning process. Furthermore, we expect that providing prompts to guide students in their 
learning process will lead to an increase in the use of regulative activities. However, since regulation of activities is a context-depended process (Paris and Paris 2001; Zimmerman 2001), different kinds of support can affect the regulation of the learning process in different ways. Finally, we expect that the use of regulative activities will lead to better learning results.

\section{Method}

Subjects and design

A total of 48 dyads $(N=96)$ from eight classes of six secondary schools in Amsterdam participated in this study. Their age ranged from 15 to 17 years. All participants were following pre-university education and took physics courses. Data were collected on two occasions and aggregated into one data set. The data of the first and second study were collected in the context of studies presented by Saab et al. (2007) and by Saab (2005) respectively. However, the data used in the present study are not yet analysed before. From the 48 dyads, 23 dyads from the first study (Saab et al. 2007), and 25 dyads from the second study (Saab 2005) participated. In both studies, the participants were randomly divided in a control and experimental group. The following sections provide more information about these studies.

\section{Learning environment and task}

All students worked collaboratively with a learning environment named Collisions. ${ }^{1}$ Collisions was developed in SimQuest (Van Joolingen and De Jong 2003) and is based on a computer simulation of colliding particles (Fig. 1). The main learning task was to discover the underlying physics rules. For example, students had to uncover the relation between the momentum of a particle before and after it hits another particle. Students could see the effect on the other variables of a performed simulation in a graph by varying the variables mass and initial velocity of the particle.

In the learning environment, students were presented with assignments that focused their attention on a specific part of collisions, such as elastic collisions, which is presented by the simulation. Assignments presented the students with small research questions that could guide the inquiry process. The assignments included multiple-choice as well as open ended questions. The environment contained three content levels of increasing complexity: Uniform motion, Fixed wall, and Elastic collisions.

When students opened a level, a window with learning goals for that level was shown. For example: 'In this level, you will find the relation between the mass (m) and the size of the momentum (p) of the ball'.

Dyads of students worked collaboratively on two computers with a shared interface, communicating through a chat channel. Students were not familiar with Collisions, but were acquainted with the variables presented in the environment from their physics classes.

In both studies, an intervention was carried out. In the first study, it was investigated whether instruction in effective communication in an inquiry learning environment can lead to more effective communicative activities, more effective inquiry learning activities, and

\footnotetext{
${ }^{1}$ Collisions was developed by Kingma and Veermans (University of Twente). SimQuest was developed in the SERVIVE-project which was coordinated by University of Twente.
} 


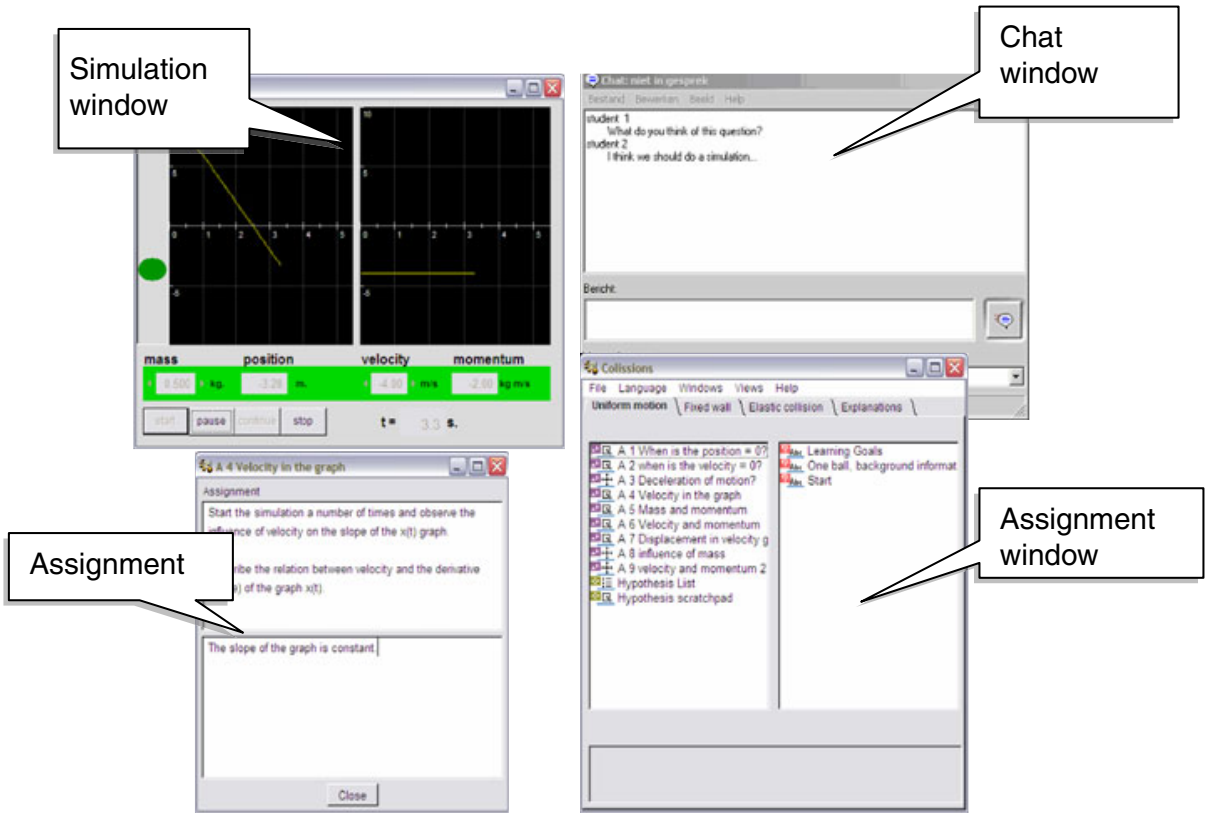

Fig. 1 Screenshot of the learning environment. Shown are the simulation window, assignment window, and chat window

improved inquiry learning results. The students were randomly divided into a control and experimental group, of which the latter received an instruction on collaboration, the RIDE rules, developed by Saab et al. (2007). In the second study, all students received the RIDE rules instruction since the instruction seemed effective in the first study, and the students in the experimental group were additionally presented with a cognitive tool, the Collaborative Hypothesis Tool (CHT), which guided them through the processes of collaborative inquiry learning (Saab 2005).

RIDE instruction The RIDE instruction (Saab et al. 2007) consists of a number of collaboration rules that were based on literature on effective collaboration (e.g., King 1997; Mercer 1996; Webb and Farivar 1994). The rules were clustered under the following four principles: Respect, Intelligent collaboration, Deciding together, and Encouragement, and presented to the student as the RIDE rules. Table 1 provides an overview of the rules and sub-rules presented in RIDE instruction.

Prior to working with the Collisions application in SimQuest, students in the experimental group received an introductory computerized instruction in the RIDE rules with which they could practice using the rules during collaboration. This instruction was developed according to the principles of the cognitive apprenticeship model or situated cognition (Hendricks 2001; Masterman and Sharples 2002): activating prior knowledge, modelling of skills, coaching, scaffolding, articulation by the students, and evaluation and reflection by the students. Students in the control group received an instruction in problem solving, which had nothing to do with the experiment. After the instruction, students in the experimental condition practiced the RIDE rules in dyads in a SimQuest simulation environment. In a second session, all students, both students in the control and experimental condition, worked with the application Collisions. The students in the experimental group 
Table 1 RIDE rules and sub-rules taught through computerized instruction

\begin{tabular}{|c|c|}
\hline RIDE Rule & Sub-rules \\
\hline (R) Respect & $\begin{array}{l}\text { Everyone will have a chance to contribute } \\
\text { Everyone's ideas will be thoroughly considered }\end{array}$ \\
\hline $\begin{array}{l}\text { (I) Intelligent } \\
\text { collaboration }\end{array}$ & $\begin{array}{l}\text { Sharing all relevant information and suggestions } \\
\text { Clarify the information given } \\
\text { Explain the answers given } \\
\text { Give criticism }\end{array}$ \\
\hline (D) Deciding together & $\begin{array}{l}\text { Explicit and joint agreement will precede decisions and actions } \\
\text { Accepting that the group (rather than an individual member) is responsible for } \\
\text { decisions and actions }\end{array}$ \\
\hline (E) Encouraging & $\begin{array}{l}\text { Ask for explanations } \\
\text { Ask till you understand } \\
\text { Give positive feedback }\end{array}$ \\
\hline
\end{tabular}

were prompted during the experiment to use the RIDE rules. After analysing the use of communicative activities, it appeared that learners that were instructed to use the RIDE rules indeed used more communicative activities associated with those rules, especially with the rules Deciding together (D) and Encouraging (E) (Saab et al. 2007).

Collaborative hypothesis tool The CHT (Saab 2005) provides students with a template that supports them in the process of formulating a syntactically correct hypothesis (see Fig. 2). In addition, the CHT let students express their trust in the formulated hypotheses on a scale from 0 to $100 \%$. The tool also provided prompting windows with instructions on how to formulate a hypothesis together, and how to plan experiments in the SimQuest environment to test the hypotheses. A conclusion window prompted the students to check whether the results of the experiment confirmed or rejected the formulated hypothesis. When the hypothesis was rejected, students were urged to follow the inquiry steps again until they found the correct hypothesis. Only the experimental group was supported with the CHT.

In the current study three conditions of dyads can be distinguished. The first condition is the one with no intervention (Control condition); this condition exists in the first study of dyads from the control group $(N=12)$. The second condition is the one in which the students received the RIDE rules instruction (RIDE condition); this condition exists in the first study of the experimental group and in the second study of the control group $(N=$ 21). The third condition exists in the second study of the experimental group $(N=15)$ (CHT condition), in which the dyads are, in addition to the RIDE rules, presented with the CHT.

\section{Procedure}

The students were randomly assigned to the dyads and to different conditions. We chose for a heterogeneous group composition in terms of prior school achievement (Saab et al. 2005, 2007), since research has shown that groups of students with different levels of school grades are more successful working together than groups of students with similar learning results (Blatchford et al. 2003). 


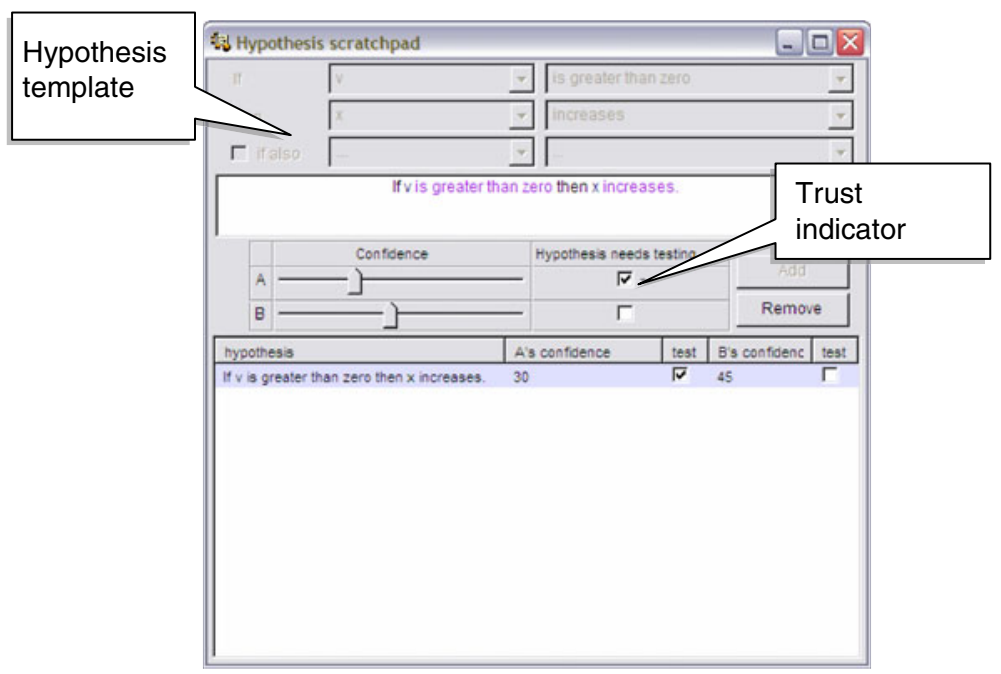

Fig. 2 Collaborative hypothesis scratchpad. Shown are the hypothesis template and the trust indicator

All students in the experimental groups received an instruction in the RIDE rules, in a session prior to working together for 90 min with the application Collisions in the learning environment SimQuest. The experimental and control groups worked with different versions of the learning environment. Table 2 presents an overview of the features of the three studies.

\section{Measuring learning process}

All communicative and inquiry learning activities were logged and were put together in a single protocol for each dyad. An analysis scheme (Table 3) to measure inquiry regulative learning activities (Njoo and De Jong 1993) was used to analyze the protocols. Team and task regulation were distinguished. Table 3 shows examples of team and task regulative activities. The analysis scheme was used in both studies.

In the protocols, each chat utterance was scored. For both studies, two independent researchers rated $10 \%$ of the protocols, after they both were trained in using the analysis scheme. Cohen's kappa of inter-rater reliability between the two raters was in both studies between .95 and .97 , which can be considered as good agreement (Fleiss 1981).

Measuring learning results

In this study, the team performance within the learning environment was measured. Students received one point for a right answered assignment if their answer was right the

Table 2 Overview of features of the two studies

\begin{tabular}{lllll}
\hline & Time on task & Intervention & Condition & N (dyads) \\
\hline Study 1 & 90 min. & RIDE instruction & 1(Control condition) +2 (RIDE condition) & 23 \\
Study 2 & 90 min. & RIDE instruction + CHT & 2 (RIDE condition) +3 (CHT condition) & 25 \\
\hline
\end{tabular}


Table 3 Analysis scheme used to analyze students' regulative and actions and interactions

\begin{tabular}{|c|c|c|c|}
\hline \multicolumn{2}{|l|}{ Task regulation } & \multicolumn{2}{|l|}{ Team regulation } \\
\hline Code & Example & Code & Example \\
\hline Orientation on task & "What is the question?" & Planning of activities & "Shall we do the simulation now?" \\
\hline Monitoring of task & "I don't get it." & Monitoring of team & "Do you understand this question?" \\
\hline Evaluation of task & "This was easy!" & & \\
\hline
\end{tabular}

first time. The percentage correct answered assignments was calculated by dividing the amount of correctly answered assignments through the total amount of answered assignments (right and wrong answered assignments). The percentage of points gained by a team is labelled as score within the learning environment in percentages (SWLEP).

\section{Results}

Firstly, an overview of frequencies of the regulative activities for each condition is presented. Secondly, the differences between task and team regulation for each condition are analyzed. Multivariate analysis of covariance is used to determine difference in task and team regulation between conditions. Finally, analysis of variance is used to discover differences in learning result between conditions and an analysis of the relation between task and team regulation and the learning result is presented.

Table 4 shows an overview of frequencies of task and team regulation for each condition. Students monitored their team most often, whereas orientation on the task was used scarcely.

A paired-samples t-test was conducted for each condition to evaluate the differences between task and team regulation (see Table 5). In all conditions students used significantly more Team regulation than Task regulation. In the Control condition, students used more Team regulation $(M=44.42, \mathrm{SD}=31.81)$ than Task regulation $(M=16.83, \mathrm{SD}=9.46), \mathrm{t}(11)=-3.84, p<.003)$. The eta squared statistic (.53) indicated a large effect size. In the RIDE condition, students used also more Team regulation $(M=97.19, \mathrm{SD}=66.48)$ than Task regulation $(M=25.05, \mathrm{SD}=14.37), \mathrm{t}$ $(20)=-5.68, p<.000)$. The eta squared statistic (.63) indicated a large effect size. And finally, students in the CHT condition used more Team regulation $(M=134.13, \mathrm{SD}=51.59)$ than Task regulation $(M=26.33, \mathrm{SD}=10.22), \mathrm{t}(14)=-8.91, p<.000)$, too. The eta squared statistic $(.86)$ indicated a large effect size

A one-way between-groups multivariate analysis of covariance (MANCOVA) was performed to detect significant differences in Task and Team regulation between dyads of students in the Control condition $(n=12)$, in the RIDE condition $(n=21)$, and in the CHT condition $(n=15)$. Overall number of messages was used as the covariate in this analysis. Preliminary assumption testing was conducted to check for homogeneity of variancecovariance matrices by using the Box's M Test of Equality of Covariance Matrices, and for multicollinearity, with no serious violations noted.

The MANCOVA revealed a significant main effect, $F(2,44)=3.95, p<.05$ : Roy's Largest Root $=.18 \eta^{2}=.15$. The univariate result that was significant is Team regulation, $F(2,45)=$ $3.41, p<.05, \eta^{2}=.13$. 


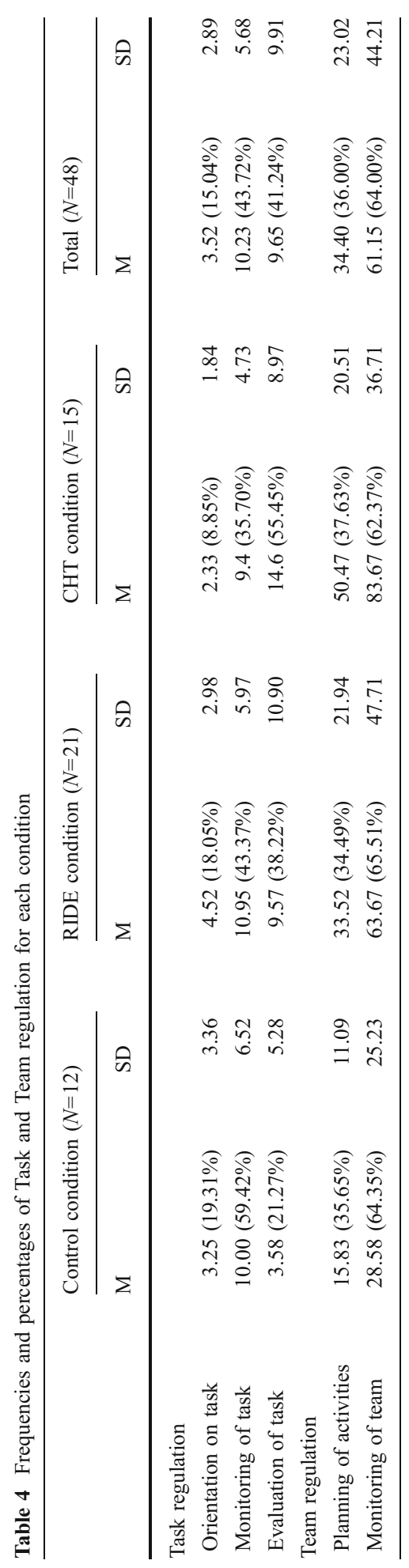


Table 5 Mean, SD, and the results of a paired $t$-test between frequencies of Task and Team regulation for each condition

\begin{tabular}{|c|c|c|c|c|c|c|c|}
\hline \multirow[t]{2}{*}{ Condition } & \multicolumn{2}{|c|}{ Task regulation } & \multicolumn{2}{|c|}{ Team regulation } & \multirow[t]{2}{*}{$t$-test } & \multirow[t]{2}{*}{$\mathrm{df}$} & \multirow[t]{2}{*}{$\mathrm{p}$} \\
\hline & M & $\mathrm{SD}$ & M & $\mathrm{SD}$ & & & \\
\hline 1. Control condition $N=12$ & 16.83 & 9.46 & 44.42 & 31.81 & -3.837 & 11 & .003 \\
\hline 2. RIDE condition $N=21$ & 25.05 & 14.37 & 97.19 & 66.48 & -5.679 & 20 & .000 \\
\hline 3. CHT condition $N=15$ & 26.33 & 10.22 & 134.13 & 51.59 & -8.906 & 14 & .000 \\
\hline
\end{tabular}

The results of a Bonferroni post hoc analysis revealed that students in the experimental conditions, the RIDE condition $(M=97.19, \mathrm{SD}=66.48)$ and the CHT condition $(M=134.13$, $\mathrm{SD}=51.59)$ produced significantly more chat messages in the team regulation category than students in the Control condition $(M=44.42, \mathrm{SD}=31.81)$, (RIDE condition: $p=.034$; CHT condition: $p=.000$ ) and revealed no significant differences between the two experimental conditions. Figure 3 shows the mean frequencies of Team and Task regulation for each condition.

An ANOVA was performed to detect differences in scores within the learning environment (SWLEP) between conditions. No significant differences between conditions were found. Table 6 shows the mean scores in percentages for each condition.

The relationships between regulation and SWLEP were investigated for each condition using Pearson product-moment correlation coefficient (See Table 7). There was a positive correlation between Team regulation and the learning results in the CHT condition $(r=.68, p<.01)$.

Fig. 3 Mean frequencies of Task and Team regulation for each condition
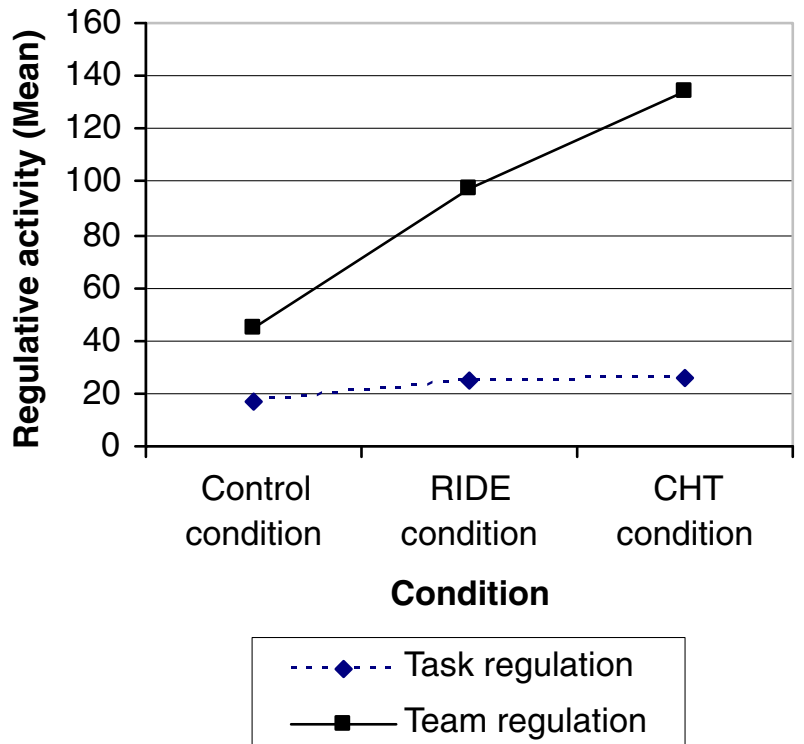
Table 6 Mean scores in percentages (SWLEP) for each condition

\begin{tabular}{|c|c|c|c|c|c|c|}
\hline & \multicolumn{2}{|c|}{ Control condition $(N=12)$} & \multicolumn{2}{|c|}{ RIDE condition $(N=21)$} & \multicolumn{2}{|c|}{ CHT condition $(N=15)$} \\
\hline & M & SD & M & SD & M & SD \\
\hline SWLEP & $55 \%$ & $.13 \%$ & $58 \%$ & $.12 \%$ & $59 \%$ & $.22 \%$ \\
\hline
\end{tabular}

Table 7 Pearson Correlations between learning result and Task and Team regulation for each condition

\begin{tabular}{|c|c|c|c|}
\hline & $\begin{array}{l}\text { Control condition learning } \\
\text { result }\end{array}$ & $\begin{array}{l}\text { RIDE condition learning } \\
\text { result }\end{array}$ & $\begin{array}{l}\text { CHT condition learning } \\
\text { result }\end{array}$ \\
\hline $\begin{array}{l}\text { Task } \\
\text { regulation }\end{array}$ & -.28 & -.20 & .32 \\
\hline $\begin{array}{l}\text { Team } \\
\text { regulation }\end{array}$ & -.37 & -.20 & $.68 * *$ \\
\hline
\end{tabular}

$* * p<0.01$

\section{Conclusion and discussion}

In this study, we have investigated how support of collaborative inquiry learning can affect the use of regulative activities of tenth-grade students who worked in pairs in a collaborative inquiry learning environment that was based on a computer simulation, Collisions, developed in the program SimQuest (Van Joolingen and de Jong 2003). We also explored the possible relations between task regulation, team regulation and learning results of students. Regulative activities of students from three different conditions are compared. Students in the Control condition did not receive any support at all. In the second condition (RIDE condition), students received an instruction in effective communication, the RIDE rules. In the third condition (CHT condition), students were, in addition to receiving the RIDE rules instruction, supported by the Collaborative Hypothesis Tool (CHT), that helped the students with formulating hypotheses together.

The results show that students overall used more team regulation than task regulation. We can conclude that in a learning environment where students are working together synchronically and from a distance the regulation of the collaborative process seems important. This is corroborated by a study by De Jong et al. (2005) and by a study by Erkens et al. (2005). De Jong and colleagues (2005) investigated student regulation of learning while students communicated through text-based CMC (computer-mediated communication). In this study, it was found that very few self-regulative activities occurred. Instead, regulation was focused more on activities such as grounding and reaching common agreement, which can be compared to team regulation in our study. In a study by Erkens et al. (2005) into studying the relation between support of the planning process and the collaborative argumentative writing process it was found that more coordination of the collaborative process resulted in better argumentative writing.

Another result we found is that in the experimental conditions (RIDE condition and CHT condition) students regulated their team activities more than students that were not supported by instruction or tools. It seems that support of the learning process, communication as well as inquiry learning process, helps students to coordinate and manage their collaborative inquiry learning process. We expected that students who 
received the RIDE instruction would benefit from their effective communication by regulating their learning process more. This is in line with other studies, where supporting students in effective communication (i.e., questioning, justifying, summarizing) enhanced monitoring, meaningful discussion and deeper thinking (Choi et al. 2005; Palinscar and Brown 1989; Brown and Campione 1994). Also, we expected the combination of the RIDE instruction and the CHT to influence the regulation of learning. Different studies have shown that students who work with complex computer-based learning environments without support have difficulties regulating their learning (e.g., Azevedo et al. 2004; Greene and Land 2000; Hill and Hannafin 1999). We found no significant differences in the use of team regulative activities between the different measures of support. The question that remains unanswered is whether the use of team regulation in a situation where students are only provided with the CHT (without the RIDE rules) differs from the use of team regulation in the RIDE condition or in the CHT condition. A possibility is that students who are only provided with the CHT will focus their team regulation more on the inquiry processes as the CHT emphasizes these inquiry processes, such as formulating hypotheses, instead of focussing for example on finding answers for the assignments. In this study, we have only investigated the frequencies of activities. In future studies, the content of the team regulation can be studied in order to answer this question.

No significant differences in learning results between conditions were found. For the CHT condition, we found a significant positive relation between the regulation of team activities and learning results. When students used more team regulation, they performed better when they received both measures of support than when they received only the RIDE instruction or no support at all. This means that an instruction in effective communication can increase the use of team regulation, but only the use of a tool that provide students with prompts on which inquiry activities they should execute in combination with team regulation will actually lead to better learning performance. However, based on this study, it is not possible to attribute this effect to the use of only the CHT or to the combination of support. Other research has faced the same problem, since most learning environments provide various kinds of support (Oliver and Hannafin 2000) which makes it difficult or not possible to state which measure affects the learning process or learning performance. Still we can state that adding the $\mathrm{CHT}$ as a scaffold affected the learning results.

Another interesting result is the lacking of significant differences in task regulation between the different conditions. Clearly, the provided support does not influence the task regulation process. Students seem to stay more focused on coordinating their collaborative process under different circumstances rather than increase the use of task regulation.

A limitation of the study is the relative short time span of the work. As the whole collaborative session lasted $90 \mathrm{~min}$, robust effects of the treatment in terms of learning outcome cannot be expected. This leads to the conclusion that different measures of support can enhance the use of team regulative activities, but that we are unable to state that they lead to better learning results, although we would expect this to be the case.

Next to the short time span of work, another limitation is that it is not clear how students in a condition with only the CHT (without the RIDE instruction) would regulate their learning process. In this study we provided the students with the CHT only in addition to the RIDE instruction. Our goal was to improve the collaborative inquiry learning process by providing the students with effective support. Since the RIDE rules seemed an effective scaffold in the first study, we presented the students in the experimental condition of the second study (the third condition) with both the RIDE rules and the CHT. A suggestion for future studies would be to also investigate the effects of the CHT on the learning process and learning results without the RIDE instruction. 
Implications

In this study, students used more team regulation when support was provided. Different researchers have stated that students are not conscious of their self-regulatory activities (e.g. Butler and Winne 1995), since most students do not reflect on their regulatory process during or after the learning process. A question that one can ask with respect to students in the present study is whether students are consciously regulating their collaboration since students did not have to reflect on their regulative learning process either.

Given that team regulation seems important in collaborative inquiry learning, students should not only learn domain specific knowledge, but they also should learn how to regulate their collaborative learning process. In this way, their learning process in diverse learning environments and situations will be improved, even when no added support is provided. Instruction in inquiry learning should therefore not only be aimed at conceptual understanding and learning, but also at the development of the use of regulatory strategies (Duggan and Gott 2002; Schraw et al. 2006).

Reflection of the regulation process can enhance the development of regulatory skills. Mirroring tools, which provide students with graphical feedback on their collaborative process, or metacognitive tools (Azevedo 2007), which provide students with visualizations of fruitful collaboration, can be used to help students reflect on their learning processes (Jermann and Dillenbourg 2008; Soller et al. 2005) .

Collaborative inquiry learning environments can provide students with instruction and tools such as the RIDE instruction and the CHT in order to increase the use of team regulation to improve learning performances. Next to these kinds of support, mirroring and/ or metacognitive tools can be build-in these learning environments in order to learn students how and when to use regulatory activities effectively.

Open Access This article is distributed under the terms of the Creative Commons Attribution Noncommercial License which permits any noncommercial use, distribution, and reproduction in any medium, provided the original author(s) and source are credited.

\section{References}

Azevedo. (2007). Understanding the complex nature of self-regulatory processes in learning with computerbased learning environments: an introduction. Metacognition and Learning, 2, 57-65.

Azevedo, R., Cromley, J. G., \& Seibert, D. (2004). Does adaptive scaffolding facilitate students'ability to regulate their learning with hypermedia? Contemporary Educational Psychology, 29, 344-370.

Baker, M., \& Lund, K. (1997). Promoting reflective interactions in a computer-supported collaborative learning environment. Journal of Computer Assisted Learning, 13, 175-193.

Blatchford, P., Kutnick, P., Baines, E., \& Galton, M. (2003). Toward a social pedagogy of classroom group work. International Journal of Educational Research, 39, 153-172.

Boekaerts, M., \& Simons, P. R. J. (1993). Leren en Instructie. Psychologie van de leerling en het leerproces. [Learning and instruction. Psychology of the student and the learning process]. Assen: Dekker \& Van de Vegt.

Brown, A. L., \& Campione, J. C. (1994). Guided discovery in a community of learners. In K. McGilly (Ed.), Classroom lessons: integrating cognitive theory and classroom practice (pp. 229-270). MIT: Cambridge.

Butler, D., \& Winne, P. (1995). Feedback and self-regulated learning: a theoretical synthesis. Review of Educational Research, 65, 245-281.

Chan, C. (2001). Peer collaboration and discourse patterns in learning from incompatible information. Instructional Science, 29, 443-479.

Chi, M. T. H., Bassok, M., Lewis, M. W., Reimann, P., \& Glaser, R. (1989). Self-explanations: how students study and use examples in learning to solve problems. Cognitive Science, 13, 145-182. 
Choi, I., Land, S. M., \& Turgeon, A. J. (2005). Scaffolding peer-questioning strategies to facilitate metacognition during online small group discussion. Instructional Science, 33, 483-511.

Cohen, E. G. (1994). Restructuring the classroom: conditions for productive small groups. Review of Educational Research, 64, 1-35.

De Jong, T. (1991). Learning and instruction with computer simulations. Education and Computing, 6(3/4), $217-229$.

De Jong, T. (2006). Scaffolds for scientific discovery learning. In J. Elen \& D. Clark (Eds.), Handling complexity in learning environments: research and theory (pp. 107-128). London: Elsevier Science Publishers.

De Jong, T., \& Njoo, M. (1992). Learning and instruction with computer simulations: learning processes involved. In E. de Corte, M. Linn, H. Mandl, \& L. Verschaffel (Eds.), Computer-based learning environments and problem solving (pp. 411-429). Berlin, Germany: Springer-Verlag.

De Jong, T., \& van Joolingen, W. R. (1998). Discovery learning with computer simulations of conceptual domains. Review of Educational Research, 68, 179-201.

De Jong, F., Kollöffel, B., Van der Meijden, H., Kleine Staarman, J., \& Janssen, J. (2005). Regulative processes in individual, $3 \mathrm{D}$, and computer supported cooperative learning contexts. Computers in Human Behavior, 21, 645-670.

Dekker, R., \& Elshout-Mohr, M. (1998). A process model for interaction and mathematical level raising. Educational Studies in Mathematics, 36, 303-314.

De Vries, E., Lund, K., \& Baker, M. (2002). Computer-mediated epistemic dialogue: Explanation and argumentation as vehicles for understanding scientific notions. The Journal of the Learning Sciences, 11 (1), 63-104.

Duggan, S., \& Gott, R. (2002). What sort of science education do we really need? International Journal of Science Education, 24(7), 661-679.

Erkens, G., Jaspers, J., Prangsma, M., \& Kanselaar, G. (2005). Coordination processes in computer supported collaborative writing. Computers in Human Behavior, 21, 463-486.

Fleiss, J. L. (1981). Statistical methods for rates and proportions. NY: Wiley.

Greene, B., \& Land, S. (2000). A qualitative analysis of scaffolding use in a resource-based learning environment involving the world wide web. Journal of Educational Computing Research, 23(2), 151-179.

Hannafin, M. J., \& Land, S. M. (1997). The foundations and assumptions of technology-enhanced studentcentred learning environments. Instructional Science, 25, 167-202.

Hendricks, C. C. (2001). Teaching causal reasoning through cognitive apprenticeship: What are results from situated learning? The Journal of Educational Research, 94(5), 302-311.

Hill, J., \& Hannafin, M. (1999). Cognitive strategies and learning from the world wide web. Educational Technology Research and Development, 45(4), 37-64.

Hmelo-Silver, C. E., \& Barrows, H. S. (2008). Facilitating collaborative knowledge building. Cognition and Instruction, 26, 48-94.

Hogan, K. (1999). Thinking aloud together: a test of an intervention to foster students' collaborative scientific reasoning. Journal of Research in Science Teaching, 36(10), 1085-1109.

Hogan, K., Nastasi, B. K., \& Pressley, M. (1999). Discourse patterns and collaborative scientific reasoning in peer and teacher-guided discussions. Cognition and Instruction, 17, 379-432.

Jermann, P., \& Dillenbourg, P. (2008). Group mirrors to support interaction regulation in collaborative problem solving. Computers and Education, 51, 279-296.

Kaartinen, S., \& Kumpulainen, K. (2002). Collaborative inquiry and the construction of explanations in the learning of science. Learning and Instruction, 12, 189-213.

King, A. (1997). ASK to THINK-TEL WHY ${ }^{\circledR}$ C: : a model of transactive peer tutoring for scaffolding higher level complex learning. Educational Psychologist, 32(4), 221-235.

Klahr, D., \& Nigam, M. (2004). The equivalence of learning paths in early science instruction: Effects of direct instruction and discovery learning. Psychological Science, 15, 661-667.

Kuhn, D., \& Pearsall, S. (1998). Relations between metastrategic knowledge and strategic performance. Cognitive Development, 13, 227-247.

Kuhn, D., Black, J., Keselman, A., \& Kaplan, D. (2000). The development of cognitive skills to support inquiry learning. Cognition and Instruction, 18, 495-523.

Lajoie, S. P. (1993). Cognitive tools for enhancing learning. In S. P. Lajoie \& S. J. Derry (Eds.), Computers as cognitive tools (pp. 261-289). Hillsdale: Erlbaum.

Linn, M. C., Davis, E. A., \& Bell, P. (2004). Internet environments for science education. Mahwah: Lawrence Erlbaum Associates.

Linn, M. C., Lee, H.-S., Tinker, R., Husic, F., \& Chiu, J. L. (2006). Teaching and assessing knowledge integration in science. Science, 313, 1049-1050.

Maruping, L. M., \& Agarwal, R. (2004). Managing team interpersonal processes through technology: a tasktechnology fit perspective. Journal of Applied Psychology, 89, 975-990. 
Masterman, L., \& Sharples, M. (2002). A theory-informed framework for designing software to support reasoning about causation in history. Computers \& Education, 38, 165-185.

Mayer, R. E. (2004). Should there be a three-strikes rule against pure discovery learning? American Psychologist, 59, 14-19.

Mercer, N. (1996). The quality of talk in children's collaborative activity in the classroom. Learning and Instruction, 6(4), 359-377.

Njoo, M. K. H. (1994). Exploratory learning with a computer simulation: learning processes and instructional support. Eindhoven: Technische Universiteit Eindhoven.

Njoo, M. K. H., \& de Jong, T. (1993). Exploratory learning with a computer simulation for control theory: learning processes and instructional support. Journal of Research in Science Teaching, 30(8), 821-844.

Okada, T., \& Simon, H. A. (1997). Collaborative discovery in a scientific domain. Cognitive Science, 21(2), $109-146$.

Oliver, K., \& Hannafin, M. J. (2000). Student management of web-based hypermedia resources during openended problem solving. Journal of Educational Research, 94(2), 75-93.

Palinscar, A., \& Brown, A. (1989). Classroom dialogues to promote self-regulated comprehension. Advances in Research on Teaching, 1, 35-71.

Paris, S. G., \& Paris, A. H. (2001). Classroom applications of research on self-regulated learning. Educational Psychologist, 36, 89-101.

Patrick, H., \& Middleton, M. J. (2002). Turning the kaleidoscope: what we see when self-regulated learning is viewed with a qualitative lens. Educational Psychologists, 37, 27-39.

Reiser, B. J. (2004). Scaffolding complex learning: the mechanisms of structuring and problematizing student work. The Journal of the Learning Sciences, 13, 273-304.

Ross, J. A., \& Cousins, J. B. (1995). Impact of explanation seeking on student achievement and attitudes. Journal of Educational Research, 89(2), 109-117.

Saab, N. (2005). Chat and explore. The role of support and motivation in collaborative scientific discovery learning. Unpublished doctoral dissertation. University of Amsterdam, Amsterdam, The Netherlands.

Saab, N., Van Joolingen, W. R., \& Van Hout-Wolters, B. H. A. M. (2005). Communication in collaborative discovery learning. British Journal of Educational Psychology, 75, 603-621.

Saab, N., Van Joolingen, W. R., \& Van Hout-Wolters, B. H. A. M. (2007). Supporting communication in a collaborative discovery learning environment: the effect of instruction. Instructional Science, 35 , 73-98.

Salovaara, H. (2005). An exploration of student's strategy use in inquiry-based computer-supported collaborative learning. Journal of Computer Assisted Learning, 21, 39-52.

Sandoval, W. A., \& Reiser, B. J. (2004). Explanation-driven inquiry: integrating conceptual and epistemic scaffolds for scientific inquiry. Science Education, 88, 345-372.

Schraw, G., \& Moshman, D. (1995). Metacognitive theories. Educational Psychology Review, 7(4), 351-371.

Schraw, G., Crippen, K. J., \& Hartley, K. (2006). Promoting self-regulation in science educatio: metacognition as part of a broader perspective on learning. Research in Science Education, 36, 111-139.

Schunk, D. (1996). Goal and self-evaluative influences during children's cognitive skill learning. American Educational Research Journal, 33(2), 359-382.

Schunk, D. H., \& Zimmerman, B. J. (1994). Self-regulation of learning and performance: Issues and educational applications. Hillsdale: Erlbaum.

Sharma, P., \& Hannafin, M. J. (2007). Scaffolding in technology-enhanced learning environments. Interactive Learning Environments, 15, 27-46.

Shute, V. J., \& Glaser, R. (1990). A large-scale evaluation of an intelligent discovery world: Smithtown. Interactive Learning Environments, 1, 51-77.

Soller, A. (2004). Computational modelling and analysis of knowledge sharing in collaborative distance learning. User modeling and user-adapted interaction. The Journal of Personalization Research, 14(4), $351-381$.

Soller, A., Martinez Monés, A., Jermann, P., \& Muehlenbrock, M. (2005). From mirroring to guiding: a review of state of the art technology for supporting collaborative learning. International Journal of Artificial Intelligence in Education, 15(4), 261-290.

Springer, L., Stanne, M. E., \& Donovan, S. S. (1999). Effects of small-group learning on undergraduates in science, mathematics, engineering, and technology: a meta-analysis. Review of Educational Research, 69, 21-51.

Toth, E. E., Suthers, D. D., \& Lesgold, A. M. (2002). The effects of representational guidance and reflective assessment on scientific inquiry. Science Education, 86(2), 264-286.

Van Boxtel, C. (2000). Collaborative concept learning. Collaborative learning tasks, student interaction, and the learning of physics concepts. Unpublished doctoral dissertation, Utrecht University, Utrecht, The Netherlands. 
Van der Linden, J., Erkens, G., Schmidt, H., \& Renshaw, P. (2000). Collaborative learning. In P. R. J. Simons, J. van der Linden, \& T. Duffy (Eds.), New learning. Dordrecht: Kluwer Academic Publishers.

Van Joolingen, W. R. (1999). Cognitive tools for discovery learning. International Journal of Artificial Intelligence in Education, 10(3-4), 385-397.

Van Joolingen, W. R., \& De Jong, T. (1993). Exploring a domain through a computer simulation: Traversing variable and relation space with the help of a hypothesis scratchpad. In D. Towne, T. De Jong, \& H. Spada (Eds.), Simulation-based experiental learning (pp. 191-206). Berlin: Springer.

Van Joolingen, W. R., \& de Jong, T. (2003). SimQuest, authoring educational simulations. In T. Murray, S. Blessing, \& S. Ainsworth (Eds.), Authoring tools for advanced technology learning environments: Toward cost-effective adaptive, interactive, and intelligent educational software (pp. 1-31). Dordrecht: Kluwer.

Van Joolingen, W. R., De Jong, T., Lazonder, A. W., Savelsbergh, E. R., \& Manlove, S. (2005). Co-lab: research and development of an online learning environment for collaborative scientific discovery learning. Computers in Human Behavior, 21, 671.

Veenman, M. V. J., Elshout, J. J., \& Meijer, J. (1997). The generality vs. domain specificity of metacognitive skills in novice learning across domains. Learning and Instruction, 7, 197-209.

Veermans, K. H., de Jong, T., \& van Joolingen, W. R. (2000). Promoting self directed learning in simulation based discovery learning environments through intelligent support. Interactive Learning Environments, 8, 229-255.

Webb, N. M., \& Farivar, S. (1994). Promoting helping behavior in cooperative small groups in middle school mathematics. American Educational Research Journal, 31(2), 369-395.

Webb, N. M., Farivar, S. H., \& Mastergeorge, A. M. (2002). Productive helping in cooperative groups. Theory into Practice, 41, 13-20.

Weick, K. E., \& Meader, D. K. (1993). Sensemaking and group support systems. In L. M. Jessup \& J. S. Valacich (Eds.), Group support systems: new perspectives (pp. 230-252). New York: MacMillan.

White, B., \& Frederiksen, J. (1998). Inquiry, modeling, and metacognition: makin science accessible to all students. Cognition and Instruction, 16(1), 3-118.

Whitelock, D., Scanlon, E., Taylor, J., \& O'Shea, T. (1995). Computer support for pupils collaborating: A case study on collisions. CSCL '95 (Computer Support for Collaborative Learning), Bloomington, Indiana (October 17-20), 1995, pp. 380-384.

Winne, P. (2005). A perspective on state-of-the-art research on self-regulated learning. Instructional Science, $33,559-565$.

Zimmerman, B. J. (2001). Theories of self-regulated learning and academic achievement: an overview and analysis. In B. J. Zimmerman \& D. H. Schunk (Eds.), Self-regulated learning and academic achievement. Theoretical perspectives (pp. 1-37). Mahwah: Lawrence Erlbaum Associates.

Zimmerman, B. J., \& Schunk, D. H. (1989). Self-regulated learning and academic achievement: Theory, research, and practice. New York: Springer. 